\title{
ANN Based Tool Condition Monitoring System for CNC Milling Machines
}

\section{Sistema basado en redes neuronales artificiales para el monitoreo de la herramienta en fresadoras CNC}

\author{
Mota-Valtierra G.C. \\ Laboratorio de Mecatrónica. Facultad de Ingeniería \\ Universidad Autónoma de Querétaro \\ Email:g.motav@hotmail.com \\ Franco-Gasca L.A. \\ CIATEQ, A.C., LabCASD, Querétaro \\ E-mail:luis.franco@ciateq.mx
}

\author{
Herrera-Ruiz G. \\ Laboratorio de Mecatrónica. Facultad de Ingeniería \\ Universidad Autónoma de Querétaro \\ Email:gherrera@uaq.mx \\ Macias-Bobadilla G. \\ Laboratorio de Mecatrónica. Facultad de Ingeniería \\ Universidad Autónoma de Querétaro \\ Email:gonzalo.macias@uaq.mx
}

Información del artículo: recibido: marzo de 2010, reevaluado: junio de 2010, aceptado: octubre de 2010

\begin{abstract}
Most of the companies have as objective to manufacture high-quality products, then by optimizing costs, reducing and controlling the variations in its production processes it is possible. Within manufacturing industries a very important issue is the tool condition monitoring, since the tool state will determine the quality of products. Besides, a good monitoring system will protect the machinery from severe damages. For determining the state of the cutting tools in a milling machine, there is a great variety of models in the industrial market, however these systems are not available to all companies because of their high costs and the requirements of modifying the machining tool in order to attach the system sensors. This paper presents an intelligent classification system which determines the status of cutters in a Computer Numerical Control (CNC) milling machine. This tool state is mainly detected through the analysis of the cutting forces drawn from the spindle motors currents. This monitoring system does not need sensors so it is no necessary to modify the machine. The correct classification is made by advanced digital signal processing techniques. Just after acquiring a signal, a FIR digital filter is applied to the data to eliminate the undesired noisy components and to extract the embedded force components. A Wavelet Transformation is applied to the filtered signal in order to compress the data amount and to optimize the classifier structure. Then a multilayer perceptron-type neural network is responsible for carrying out the classification of the signal. Achieving a reliability of $95 \%$, the system is capable of detecting breakage and a worn cutter.
\end{abstract}

\section{Keywords}

- breakage

- wear

- Wavelet transform

- artificial neural networks

- monitoring system

- FIR filter 


\section{Resumen}

Algunas empresas tienen como principal objetivo ofrecer a sus clientes productos de calidad, y esto es posible optimizando sus costos, reduciendo y controlando las variaciones en sus procesos de producción. Dentro de las industrias manufactureras el estado físico de las herramientas es muy importante, ya que de esto depende en gran medida la calidad del producto y la vida útil de la maquinaria. Actualmente existe en el mercado una gran variedad de sistemas de monitoreo para determinar el estado de los cortadores en las fresadoras; sin embargo, estos son costosos e inaccesibles para las empresas pequeñas y frecuentemente es necesario hacer modificaciones a la maquinaria para instalarlos. En este artículo se presenta un sistema de monitoreo con un clasificador inteligente que determina el estado de las herramientas de corte en una fresadora de Control Numérico por Computadora (CNC). El estado de los cortadores se detecta a través del análisis de las fuerzas de corte que se encuentran contenidas en las corrientes del motor del husillo. Algo importante en este sistema es que no utiliza sensores ni es necesario hacer modificaciones para adherirlo al proceso original. Para lograr la clasificación se aplican técnicas de procesamiento digital de señales, para eliminar los componentes de ruido y extraer los componentes de fuerza, se aplica a la señal original un filtro digital del tipo FIR. Después, se aplica una transformada Wavelet, con la finalidad de comprimir la información y optimizar el clasificador. Por último, una red neuronal del tipo perceptrón multicapa es la encargada de realizar la clasificación de las señales, alcanzando una confiabilidad del 95\%. El sistema es capaz de detectar la ruptura y el desgaste del cortador.

\section{Introduction}

The aim of most of the companies is to satisfy the needs of its costumers by producing high quality products, optimizing costs and improving the manufacturing processes. So, in order to achieve the quality specifications it is very important to eliminate variations during the production processes. For manufacturing companies, the use of tool condition monitoring systems is mandatory in order to detect either breakage or wear on the tools. These systems avoid the production of poor quality pieces due to the state of the cutting tools and even prevent damage to the machines.

The techniques used in sound and vibration emission sensing have the disadvantage of capturing signals from nearby equipment, making difficult to identify the desired information in the machining process. Image processing based monitoring systems have been already developed; but with this kind of systems the monitoring must be done off-line, stopping the process completely while the tool analysis is completed (Franco, 2008). The Artificial Neural Networks (ANNs) offer the possibility to work in parallel, making possible the real time monitoring.

In most of the reported methods and systems, the use of sensors is common (Prickett et al., 1999; Franco, 2008); however, the sensor selection is one of the most critical aspects in the system development, since its application is limited by the operation range defined by the manufacturer specifications. Because of this, tool condition monitoring systems are fitted to certain specific working conditions that do not allow nor ease the adjustment to new manufacturing operations. Since the sensor approach presents the inconvenience that each machine requires its own characteristic sensor system, adaptability becomes a desirable characteristic of any monitoring system. Because of its ability for adapting to changes, besides the big number of inputs, all those problems do not occur with the use of ANNs.

For manufacturing companies the use of tool condition monitoring systems is mandatory in order to detect either breakage or wear on the tools, and to avoid the production of poor quality pieces due to the state of the cutting tools and even prevent the damage to the machines.

In most of the reported methods and systems, the use of sensors is common; however, the sensor selection is one of the most critical aspects in the system development, since its application is limited by the operation range defined by the manufacturer specifications. Therefore, tool condition monitoring systems are fitted to certain specific working conditions that do not allow nor ease the adjustment to new manufacturing operations. Since the sensor approach presents the inconvenience that each machine requires its own characteristic 
sensor system, adaptability becomes a desirable characteristic of any monitoring system, and this problem is not present in the monitoring system presented because it does not have sensors.

Thus this kind of systems is inaccessible for small companies, where the tool inspection is made by the operator of machinery, but a person does not guarantee the correct damage detection due to the inappropriate conditions such as lighting, noise, position of the tool, etc. For these reasons an intelligent system of low cost and easy incorporation to the original process is proposed. It is able to classify the physical condition of the cutting tool in a milling machine, helping to prevent defects in the working pieces and to avoid severe damage to the machine tool.

An intelligent system may be implemented with any of the artificial intelligent techniques such as artificial neural networks (ANNs), fuzzy system or heuristic algorithms. However, the use of ANNs to classify the state of the tools is widespread because of their adaptive learning, self-organization, fault tolerance and real-time operation, providing good solutions to classification or decision making problems. Examples of ANNs applied to the tool condition classification may be found in Rivero (2008), Mehrabian et al. (2008), Patra et al. (2007) and Kuljanic et al. (2009). Jantunen (2002) reported a summary of methods used to detect breakage and wear of the cutting tools, showing that cutting forces are commonly used to classify the tool wear, also, this fact may be appreciated in works presented by Kuljanic et al. (2005), Rivero et al. (2008), Bhattacharyya et al. (2007) and Jemielniak et al. (2008). In order to evaluate the cutting forces, Zuperl et al. (2004) and Kurt (2009) developed simulation models, these models determine the cutting forces with more precision than the analytical models due to the application of Multi Layer Perceptron (MLP) type ANNs.

\section{Development}

\section{Monitoring system}

Literature suggests a big variety of parameters in machining processes that can be used to characterize, to analyze and to predict the state of the cutting tools. In Prickett (1999), the monitoring mechanisms for detecting the tool condition are classified either by the place or by the variable. Among the used variables are the cutting forces (static and dynamic), since it has been widely established that forces variations are correlated to the tool wear. In practice the application and interpretation of this parameter may be studied in several forms, such as those based on the changes of the friction between the cutting tool and the work-piece (López et al., 2006; Shao et al., 2004). For this paper it was decided to analyze the cutting forces in order to determine the level of tool wear.

A retrofitted Tos kurim CNC milling machine, model FNK25A, with a head tool of two carbide inserts was used for testing the intelligent classifier. The correct set up of cutting parameters is an important step of the milling process; the parameters selection depends on the material hardness, type of cutter and work piece finish, among others. These choices will determine whether or not the final product meets the quality specifications (dimensions, finish, etc.). The stages that compose a milling process are show in figure 1.

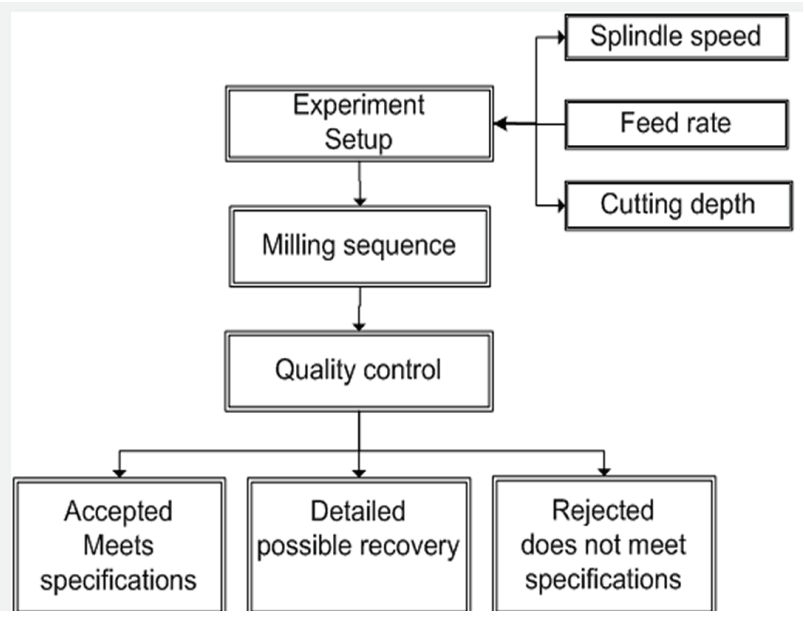

Figure 1. Stages of a milling process

The milling parameters are shown in table 1 . The milling process was made on ASTM-4130 steel, and using cutters of different states such as new (good conditions), worn (with several degrees of wear) and broken. These parameters have a big influence in the milling process, for this reason they are considered important inputs in the ANN, these parameters are provided by the operator. Moreover, there are inputs to the system (cutting forces) which are acquired from the driver.

Table 1. Milling parameters

\begin{tabular}{lcc}
\hline \multicolumn{1}{c}{ Parameter } & Value & \\
\hline Spindle speed & $300-450$ & $\mathrm{rpm}$ \\
Cutting depth & $1-1.5$ & $\mathrm{~mm}$ \\
Feed rate & $100-120$ & $\mathrm{~mm} / \mathrm{min}$ \\
\hline
\end{tabular}

The values of spindle speed, depth of cut and feed rate were varied between the ranges shown in table 1 for 


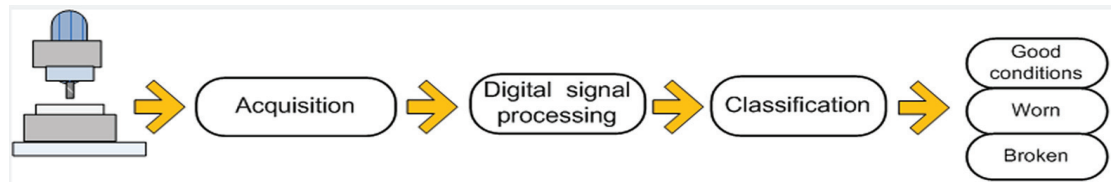

Figure 2. Stages of the monitoring system

each case. Driver current monitoring is the best approach to acquire signals without sensors because this way the machine is not modified, even when current sensors are used. In addition, the current from servomotors is available in almost all modern rotating machinery as turning, milling and drilling, directly from the servodriver. Signals from the motor spindle driver Baldor series $15 \mathrm{H}$ are acquired for determining the cutter status; these signals are a direct representation of the cutting forces, a Tektronik MSO4000 oscilloscope is the instrument used to acquire and store the signals during the process in order to create a data base, but it is used temporarily. Finally, to obtain the neural networks inputs, a features extraction from the acquired data is made by digital signal processing techniques (figure 2).

\section{Data acquisition}

As mentioned before, the cutting forces will be the main parameter to be analyzed. According to Prickett (1999) one of the points where is possible to acquire these signals is the spindle motor. Thus for avoiding the use of sensors, in this research the motor driver is proposed as the data source. The original signal presents the cutting force as its main component; however, it is important to mention that signals from the servo driver have severe noise interference by the ball-screw and the switching noise due to the associated digital systems (Romero et al., 2003). Therefore, previously to the digital processing it is necessary to filter the spindle current signals. Figure 3 shows the signal processing system, which was used to obtain the cutting forces.

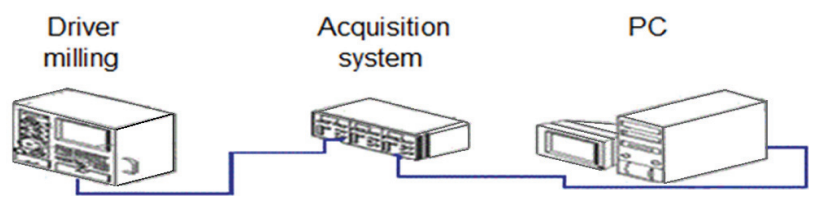

Figure 3. Experiment setup

To eliminate the noisy components, the original signal is filtered using a band-pass filter. A Finite Impulse Response (FIR) digital filter was chosen because it has a linear phase response. Table 2 contains the parameters
Table 2. Filter parameters

\begin{tabular}{lc}
\hline & Filter characteristics \\
\hline Filter type & Bandpass \\
Design method & Kaiser window \\
Sampling frequency & $6250 \mathrm{~Hz}$ \\
Order Filter & 30 \\
Cutoff frequencies & fc1 $20 \mathrm{~Hz}$ \\
& fc2 $138 \mathrm{~Hz}$ \\
\hline
\end{tabular}

of the applied filter; this was designed using the filter design and analysis tool from MatLab.

In order to determine the filter characteristics for this ANN-based tool condition monitoring system, two previous researches were applied. In Romero et al. (2003) a driver current analysis for the milling machine is presented; it has been shown that cutting forces are in a frequency range of $1-10 \mathrm{KHz}$. The choice of the sampling frequency is determined by both the characteristics of the acquisition system and the signal processing technique. And then from a filtering analysis (Franco et al., 2008) for several techniques and machining processes is found that the appropriate order filter for this kind of signals is around 40.

Figure 4 displays an unfiltered signal a) and its corresponding filtered signal b). As can be seen the filtering process removes the noisy components and preserves the embedded cutting force.

To consolidate the classification process a data compression procedure is performed. This is done by the Wavelet Transform (WT), which implements a mapping of the time-domain to a time-scale representation, preserving the temporal aspect. Figure 5 shows a signal with different compression levels by applying a Daubechies-5 Wavelet function; it can be observed that those levels have the same pattern but a different resolution. The maximum transformation level is determined by the desired data compression which results in a signal without loss of information and resolution for the next processing stage, as showed in previous research (Franco et al., 2009; Romero et al., 2003), for this study the fifth level was selected, this allows to achieve a data reduction from 1024 to only 32 points per sample. 

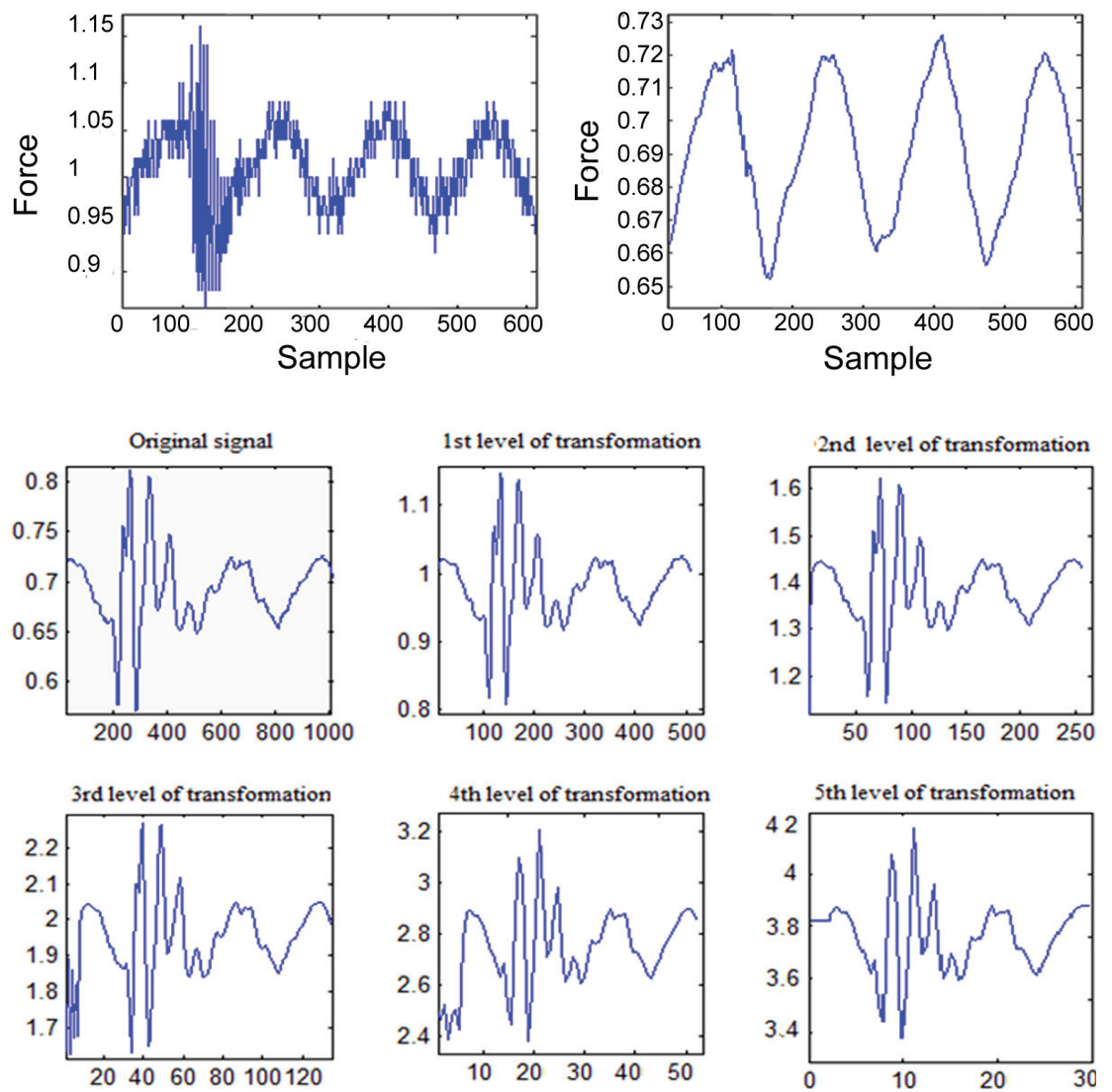

Figure 4. a) Unfiltered signal, b) Filtered signal

\section{Intelligent classification}

In order to select the optimal network for classification of the tool state, several Multi Layer Perceptron (MLP) type networks with supervised training were tested. As well as Self-Organizing Maps (SOM) with both supervised and unsupervised training, this represents a significant variation because SOM networks are usually unsupervised trained. Some of the tested MLP networks included the $[4,10,10,3],[4,8,8,3],[4,8,12,3]$ and $[4,8,10,3]$ structures. Figure 6 shows one of the MLP tested. The activation function is a sigmoid function and learning rate of 0.2 .

It was decided to test a SOM network as classifier, due to its low sensitivity to noise; it is an appropriate

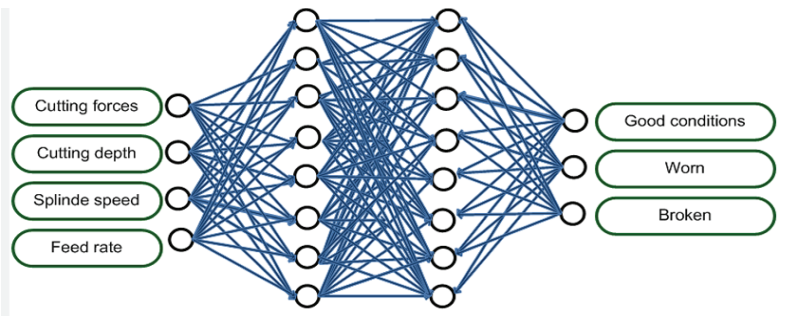

Figure 6. Multilayer Perceptron [ [ $\left.\begin{array}{llll}4 & 8 & 8 & 3\end{array}\right]$ tool to classify this kind of signals. Some of the analyzed structures were $[4,4],[4,8]$ and $[88]$, these were trained using both supervised and unsupervised learning. The supervised training was made adding a supervisor agent, which is an array of [N 1], where $N$ is the number of existing classes. Figure 7 shows a [4, 4] SOM network with a neighborhood of 1 .

The classifier was tested using two different kinds of ANNs with different size and training types. The MLP networks were preferred because their training is faster than the training of the SOM networks. There are differences in the networks performance, but they are not significant. As summary, the table 3 shows the achieved error during the training of the MLP networks.

Figure 8 shows the way as the error decreases, and it can be seen that there is not an important difference among the obtained errors when the number of neurons in the hidden layers is bigger than eight. So that, the neural network that is considered as suitable for using in the proposed intelligent classifier should have at less eight neurons in the hidden layers. For validating the network performance two types of inputs were tested, signals previously used during the training and signals not used for the training process. 


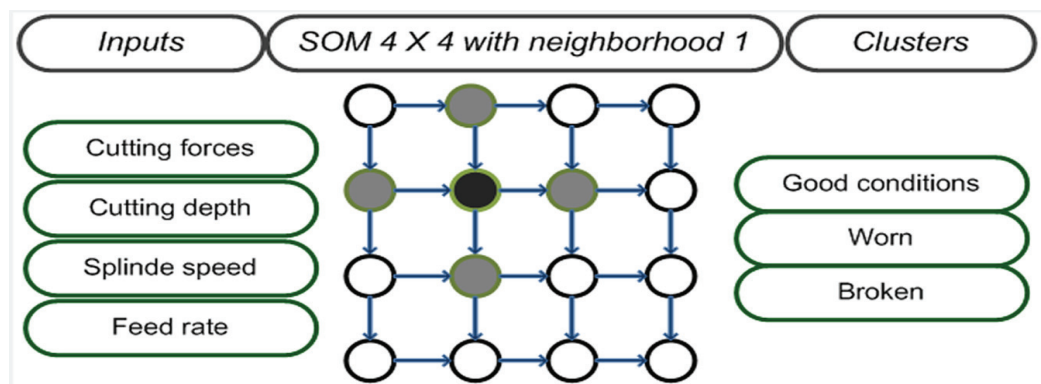

Table 3. Error of MLP networks

\begin{tabular}{cccccc}
\hline $\begin{array}{c}\text { Cutting } \\
\text { depth }(\mathbf{m m})\end{array}$ & $\begin{array}{c}\text { Feed rate } \\
(\mathbf{m m} / \mathbf{m i n})\end{array}$ & $\begin{array}{c}\text { Spindle speed } \\
(\mathbf{r p m})\end{array}$ & Epoch & $\begin{array}{c}\text { Neuron in } \\
\text { hidden layers }\end{array}$ & Error \\
\hline $\mathbf{1}$ & 100 & 300 & 1000 & {$[8,8]$} & 0.001397 \\
$\mathbf{1}$ & 100 & 450 & 1000 & {$[8,8]$} & 0.001298 \\
$\mathbf{1}$ & 120 & 300 & 1000 & {$[10,10]$} & 0.00099 \\
$\mathbf{1}$ & 120 & 450 & 1000 & {$[10,10]$} & 0.00099 \\
$\mathbf{1 . 5}$ & 100 & 300 & 1000 & {$[8,10]$} & 0.00099 \\
$\mathbf{1 . 5}$ & 100 & 450 & 1000 & {$[8,10]$} & 0.00099 \\
$\mathbf{1 . 5}$ & 120 & 300 & 1000 & {$[8,12]$} & 0.00099 \\
$\mathbf{1 . 5}$ & 120 & 450 & 1000 & {$[8,12]$} & 0.00099 \\
\hline
\end{tabular}

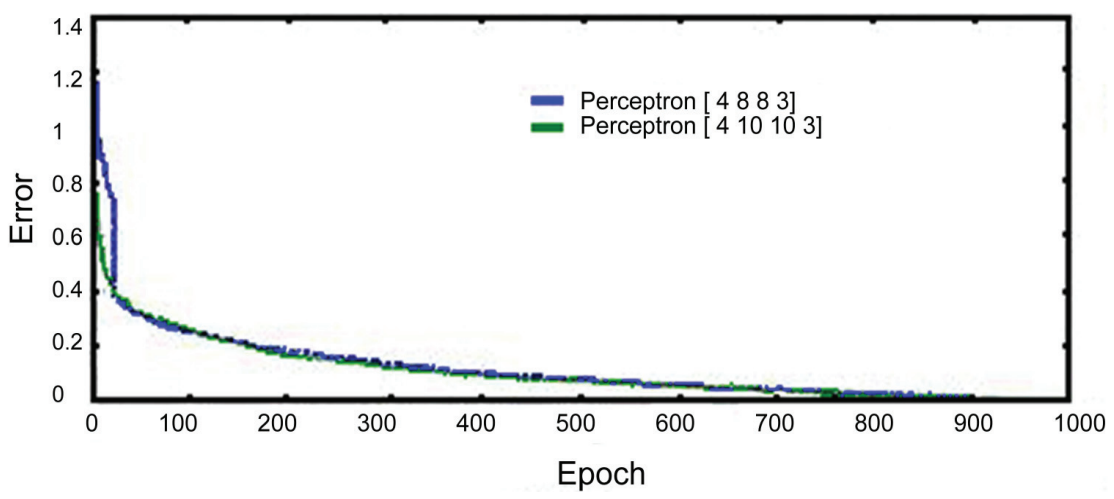

Figure 8. Error during neural network training
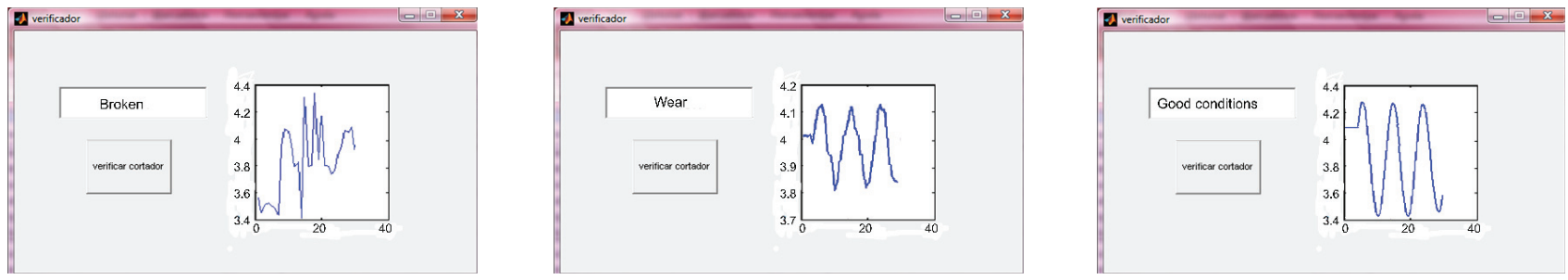
network
Figure 7. SOM-type artificial neural

Figure 9. Status classification of tool

For testing the monitoring system were used both new and worn cutting tools. Some of the worn cutters were used during the training. To guarantee a good classification system it must identify either a broken or worn cutter. Figure 9 shows some results of correct identifications. 
nitoring of the tool, besides the system presents the advantage of not having to stop the machine for knowing the tool condition. From test using both networks types, MLP and SOM, the MLP obtained a better percentage of correct classifications and a faster convergence. The presented tool condition monitoring system does not need sensors, thus the machinery will not be modified if the system is attached to its structure.

It is possible to state that there is not a significant difference in the achieved error when the neural networks have more than 8 neurons in their hidden layers; however, computationally it represents a considerable difference in resources consumption, for that reason is not appropriate to comprise more than 8 neurons per layer. So this is the suitable size for a network which is going to be considered as classifier in the proposed system.

The proposed neural network is able to classify breakage levels greater than $0.5 \mathrm{~mm}$ with a confidence level of $95 \%$; with the same confidence level it also determines the good condition of the tool. The wear tool can be resolved with an efficiency of $93 \%$ when the wear is greater than $0.25 \mathrm{~mm}$. Its reliable confidence level avoids the damage to the machinery, the tool and the piece, which is the main objective of a tool condition monitoring system. In the worst case if the monitoring system fails the workpiece will need to be re-worked with a new cutting tool, since the damage will be just a piece of a lower quality finish. Future work will try to identify two levels of wear tool, in addition to the breakage and the good working conditions.

The maximum compression level of the signal was achieved with five levels of data processing. To verify that the original signal may be recovered, an inverse wavelet transformation was made, verifying that the signal is completely recoverable.

\section{Acknowledgments}

The first author would like to thank to CONACyT for supporting this work under scholarship number 173432 .

\section{References}

Bhattacharyya P., Sengupta D., Mukhopadhyay S., Cutting ForceBased Real-Time Estimation of Tool Wear in Face Milling Using a Combination of Signal Processing Techniques. Mechanical Systems and Signal Processing, 21:2665-2683, 2007.
Franco-Gasca L.A., Romero-Troncoso R. de A., Herrera-Ruiz G., Peniche-Vera R. del R. Reconfigurable Filtering System for Sensorless Signal Acquisition in Machining Processes. International Journal of Advanced Manufacturing Technology, 38:102109, 2008.

Franco-Gasca L.A., Romero-Troncoso R. de A., Herrera-Ruiz G., Peniche.Vera R. del R. FPGA Based Failure Monitoring System for Machining Processes. International Journal of Advanced Manufacturing Technology, 40:676-686, 2009.

Jantunen E. A Summary of Methods Applied to Tool Condition Monitoring in Drilling. International Journal of Machine Tools \& Manufacture, 42:997-1010, 2002.

Jemielniak K., Arrazola P.J. Application of AE and Cutting Force Signals in Tool Condition Monitoring in Micro-Milling. CIRP Journal of Manufacturing Science and Technology, 1:97-102, 2008.

Kuljanic E., Totis G., Sortino M. Development of an Intelligent Multisensor Chatter Detection System in Milling. Mechanical Systems and Signal Processing, 23:1704-1718, 2009.

Kurt A. Modelling of the Cutting Tool Stresses in Machining of Inconel 718 Using Artificial Neural Networks. Expert Systems with Applications, 36(6):9645-9657, 2009.

Kuljanic E., Sortino M. A Method Based on Cutting Forces Monitoring Tool Wear in Face Milling. International Journal of Machine Tools \& Manufacture, 45:429-34, 2005.

López de Lacalle L.N., Lamikiz A., Sánchez J.A., Fernández de Bustos I. Recording of Real Cutting Forces Along the Milling of Complex Parts. Mechatronics, 16:21-32. 2006.

Mehrabian A., Menha-Mohammad B. A Real-Time Neuro-Adaptive Controller with Guaranteed Stability. Applied Soft Computing, 8:530-542, 2008.

Patra K., Pal-Surjya K, Bhattacharyya K. Artificial Neural Network Based Prediction of Drill Flank Wear From Motor Current Signals. Applied Soft Computing, 7:929-935, 2007.

Prickett P.W., Johns C. An Overview of Approaches to End Milling Tool Monitoring. International Journal of Machine Tools $\mathcal{E}$ Manufacture, 39:105-122, 1999.

Rivero A., Lopez de Lacalle L.N., Penalva M.L. Tool Wear Detection in Dry High-Speed Milling Based Upon the Analysis of Machine Internal Signals. Mechatronics, 18(10):627-633, 2008.

Romero-Troncoso R.J., Herrera-Ruiz G., Terol-Villalobos I., Jáuregui-Correa J.C. Driver current Analysis for Sensorless Tool Breakage Monitoring of CNC Milling Machines. International Journal of Machine Tools \& Manufacture, 43:1529-1534, 2003.

Shao H., Wang H.L., Zhao X.M. A Cutting Power Model for Tool Wear Monitoring in Milling. International Journal of Machine Tools \& Manufacture, 44:1503-1509, 2004.

Zuperl U., Cus F. Tool Cutting Force Modelling in Ball-End Milling Using Multilevel Perceptron. Journal of Materials Processing Technology, 153-154, 2004. 


\section{About the authors}

Georgina del Carmen Mota-Valtierra. She is an electronics engineer graduated from the Technological Institute of Celaya, Mexico. She received her M.Sc. degree in digital electronics from the Technological Institute of Celaya, Mexico, in 2008. She is a Ph.D. student and professor in the Faculty of Engineering in the University of Queretaro. Her current research interests are design of FPGA-based systems and artificial intelligent.

Luis Alfonso Franco-Gasca. He received his M.Sc. degree from the University of Guanajuato, Mexico, in 2000, his Ph.D. degree from the Autonomous University of Queretaro, Mexico, in 2007. Currently, he is a researcher in the Automatic Control and Dynamic Systems Laboratory at the Advanced Technology Center, CIATEQ (Queretaro, Mexico). He is member of the National Researchers System (SNI). His main current research interests include digital signal processing, intelligent control algorithms and FPGA embedded systems applications.

Gilberto Herrera-Ruiz. He received his B.Sc. degree in electronic systems engineering, his M.Sc. degree in electrical engineering and his Ph.D. degree in mechanical engineering. He is member of the National Researchers System (SNI) level II. Currently, He is the principal of the Faculty of Engineering in the Autonomous University of Queretaro. His current research interests include automation of machine tools, digital signal processing and control systems.

Gonzalo Macias-Bobadilla. He is an electronics engineer graduated from the Autonomous University of Nayarit, Mexico. He received his M.Sc. degree in instrumentation and automatic control from the Autonomous University of Queretaro, Mexico, in 2007. He is a Ph.D. student and professor in the Faculty of Engineering in the University of Queretaro. His current research interests are hardware description languages and design of FPGA-based systems. 